\title{
From the Editor
}

Congratulations are extended to Robin with the publication of this important issue of WORK devoted to care work. I remember when I first spoke with Robin about the idea of this special issue. Robin enthusiastically accepted the role as guest editor and through a great deal of hard work and determination, the issue is now a reality. The articles composing the special issue will add to the science and evidence in this area.

Also included in this issue are three regular articles. They are:

- Health Promoting Leadership - Different Views of the Concept

- Factors affecting burnout and work engagement in teachers when entering
- Safety performance: The mediating role of safety control

I know you will find these articles very informative. As always, I welcome hearing from you. If you would like to learn more about my activities, please follow me on Twitter @ KarenJacobsOT or Facebook and Linkedin.

\section{Cheers}

Karen

Editor

E-mail: kjacobs@bu.edu 